\title{
Effect of Temperature and Strain Rate on the Brittleness of China Sandstone
}

\author{
Xiuyuan Yang $\mathbb{D}^{1,2,3}$ Zhenlong Ge $\mathbb{D}^{1},{ }^{4}$ Qiang Sun $\mathbb{D}^{4},{ }^{4}$ and Weiqiang Zhang $\mathbb{D}^{1,2}$ \\ ${ }^{1}$ Key Laboratory of Coalbed Methane Resources and Reservoir Formation Process of the Ministry of Education, China University of \\ Mining and Technology, Xuzhou, Jiangsu Province 221116, China \\ ${ }^{2}$ School of Resources and Geosciences, China University of Mining and Technology, Xuzhou, Jiangsu Province 221116, China \\ ${ }^{3}$ Center for Hydrogeology and Environmental Geology, China Geological Survey, Baoding, Hebei Province 071051, China \\ ${ }^{4}$ College of Geology and Environment, Xi'an University of Science and Technology, Xi'an, Shaanxi Province 710054, China
}

Correspondence should be addressed to Zhenlong Ge; gezhenlong04@cumt.edu.cn

Received 25 August 2021; Revised 28 October 2021; Accepted 11 November 2021; Published 7 December 2021

Academic Editor: Shi-bing Huang

Copyright (C) 2021 Xiuyuan Yang et al. This is an open access article distributed under the Creative Commons Attribution License, which permits unrestricted use, distribution, and reproduction in any medium, provided the original work is properly cited.

To quantitatively study the influence of temperature and strain rate on the brittleness of sandstone, the mechanical parameters of sandstone under different temperatures and strain rates are collected from the previous literature, and two empirical equations for calculating rock brittleness are used to quantitatively calculate and evaluate the brittleness of sandstone. The results show that both $\mathrm{BI}_{1}$ and $\mathrm{BI}_{2}$ can characterize the brittleness of sandstone, but the applicable conditions are different. The $\mathrm{BI}_{1}$ method is more accurate in calculating the variation in the sandstone brittleness with a strain rate, while the $\mathrm{BI}_{2}$ method is more accurate in calculating its variation with temperature. The brittleness of sandstone increases with the increase in the strain rate, especially when the strain rate exceeds $100 \mathrm{~s}^{-1}$. Under low-temperature conditions, the strength and brittleness of rocks increase due to the strengthening of ice. Under the condition of high temperature, the thermal damage to sandstone is intensified after $400^{\circ} \mathrm{C}$, and the quartz phase changes after $600^{\circ} \mathrm{C}$, which leads to the increase in microcrack density and the decrease in brittleness of sandstone. The conditions of low temperature and high strain rate are beneficial to the enhancement of sandstone brittleness.

\section{Introduction}

Brittleness is a very important property of rock. It can be used as an index of safety risk in resource exploitation and engineering construction projects. For example, brittleness is an important property for shale gas compressibility measurement and evaluation and is a basic parameter for reservoir evaluation. Rock bursts are directly related to the brittle fracture of rock masses and the instability failure of surrounding rock structures [1]. Brittleness also is a key index of rock drillability, which plays an important role in improving tunneling speed and reducing tool wear [2]. Therefore, it is important to evaluate the brittleness of rock accurately in the process of resource development and engineering construction.

Definitions of brittleness vary across disciplines and fields, and at present, there is no unified definition. Nevertheless, many scholars have carried out in-depth research on the brittleness of rock and established different evaluation indexes of brittleness [3, 4]. For example, Jarvie et al. [5] defined the percentage of brittle minerals in rocks as a BI. Altindag [6] defined the BI of rock as the ratio of compressive strength to tensile strength. There are many definitions of BI based on curve shapes [7-9] and energy relationships [10] in stress-strain curves. Hucka and Das [11] defined a $\mathrm{BI}$ as the ratio of elastic strain to total strain in a stressstrain curve. Tarasov and Potvin [12] defined a BI for rocks as the ratio of rupture energy to excess (released) energy.

Temperature is one of the important factors affecting rock mechanical properties. Geotechnical engineering and artificial freezing engineering in cold areas make the surrounding rock of the engineering structure be subject to periodic low-temperature effects or long-term lowtemperature freezing, and its strength characteristics are very different from normal temperature conditions. Under high-temperature conditions, sandstone produces thermally 


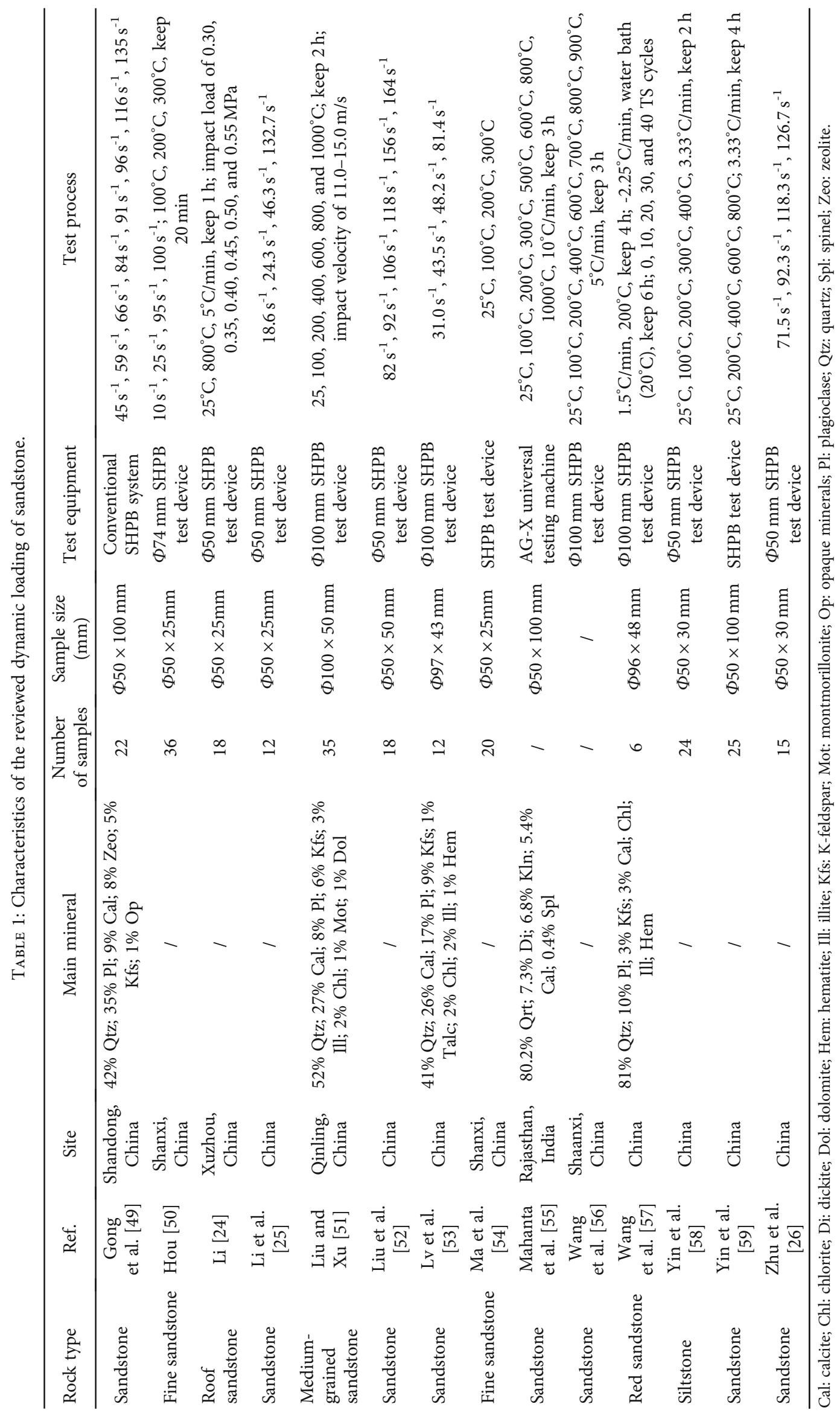




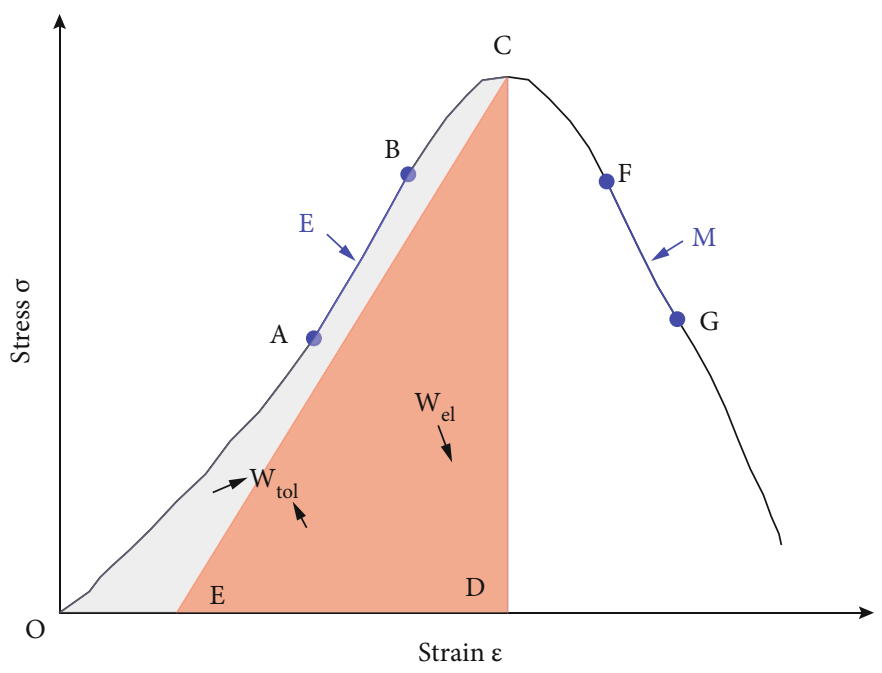

FIGURE 1: Stress-strain curve of brittle rock.

induced cracks, which affect its strength and integrity and brings great hidden dangers to engineering constructions. Therefore, it is necessary to understand the mechanical behavior of rock under different temperature conditions. On the other hand, underground engineering construction often involves ore and rock crushing, pile driving, explosives, and other engineering techniques, which are almost all related to fracturing and stress wave propagation in rocks under impact loads. This is related to the dynamic mechanical properties of rock.

At present, there has been much in-depth research on the influence of different temperatures and strain rates on the physical and mechanical properties of rocks. However, there are relatively few studies on the evaluation of rock brittleness under these two influencing factors. Based on this, this study selected sandstone as the research object and studied the effects of temperature and strain rate on the brittleness of sandstone.

\section{Experimental Results of Previous Studies}

In previous experiments, some researchers focused on the influences of tensile strength, mineral composition, and other factors on the brittleness of the specific rocks, while neglecting important common characteristics. In this paper, we summarized the effects of the strain rate and different treatment temperatures on the brittleness of sandstone based on the previous research results, as shown in Table 1. In these studies, sandstone is collected from different areas and processed into different sizes and then treated at different temperatures. With different loading rates, the impact load test or static compression test of sandstone treated at different temperatures was carried out with SHPB, and the stress-strain curves under different test conditions were obtained. In this paper, the brittleness of sandstone is quantitatively calculated according to these stress-strain curves, to explore the influence of temperature and strain rate on the brittleness of sandstone.

\section{Methods of Calculating Rock Brittleness}

After many years of theoretical exploration, researchers have put forward nearly 80 brittleness indexes (BI) of rock [13]. Because of differences in test conditions, some of these indexes can reflect differences in rock brittleness, while others need further experiments to verify their accuracy. In this study, based on stress-strain curves, two typical empirical formulas for evaluating rock BI are selected [14] (formulas (1) and (2)).

$$
\mathrm{BI}_{1}=\frac{E}{M}
$$

where $E$ is the prepeak elastic modulus and $M$ is the postpeak elastic modulus.

$$
\mathrm{BI}_{2}=\frac{W_{\mathrm{el}}}{W_{\mathrm{tot}}},
$$

where $W_{\mathrm{el}}$ is the elastic energy at failure and $W_{\text {tot }}$ is the total energy at failure.

As shown in the stress-strain curve in Figure $1, \mathrm{BI}_{1}$ is approximately the ratio of the $\mathrm{AB}$ segment to the FG segment. $\mathrm{BI}_{2}$ is equal to the ratio of the areas for $\mathrm{CDE}$ and $\mathrm{OABCD}$ in the stress-strain curve in Figure 1.

\section{Analysis and Discussion}

4.1. Influence of the Strain Rate. Figure 2 shows the relationship between the brittleness index and strain rate calculated by formulas (1) and (2). As shown in Figure 2(a), there is an overall increasing trend in $\mathrm{BI}_{1}$ with an increasing strain rate. When the strain rate is lower than $100 \mathrm{~s}^{-1}, \mathrm{BI}_{1}$ slowly increases from 0.2 to about 0.7 . When the strain rate is between $100 \mathrm{~s}^{-1}$ and $180 \mathrm{~s}^{-1}, \mathrm{BI}_{1}$ increases rapidly from 0.7 to about 2.5. As shown in Figure 2(b), $\mathrm{BI}_{2}$ decreases with the increase in the strain rate. When the strain rate is lower 


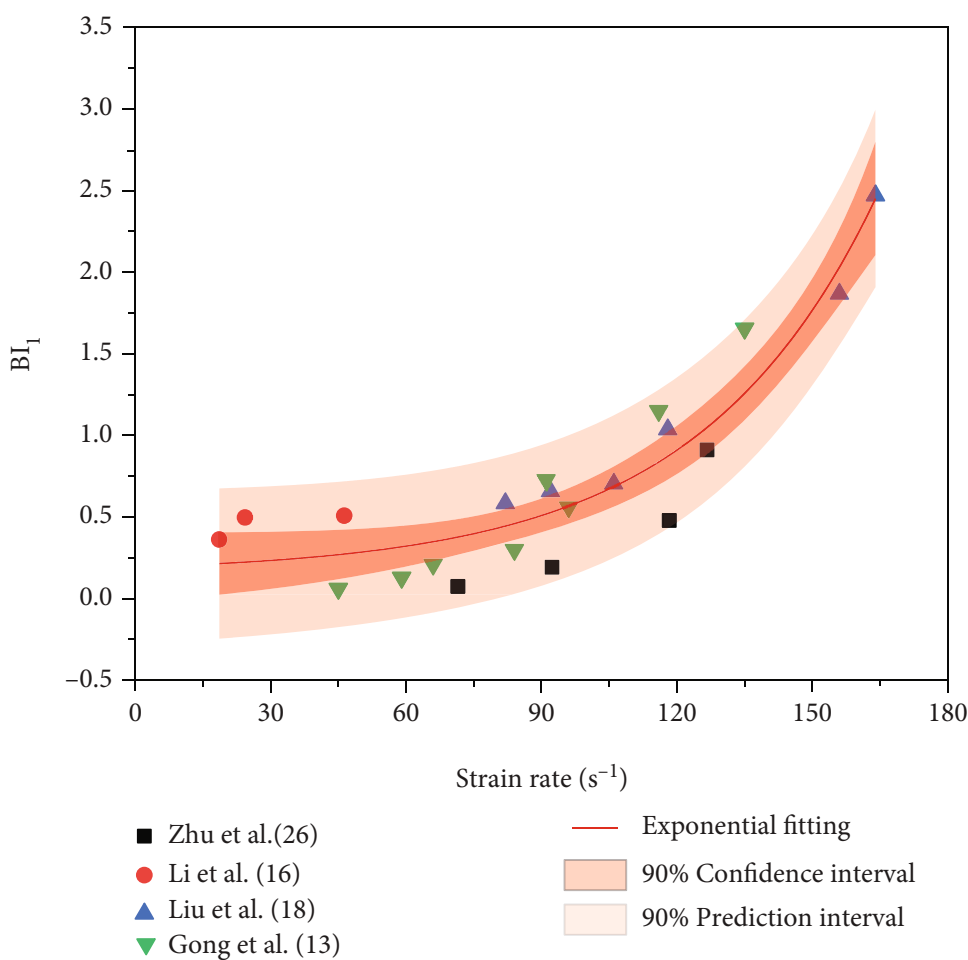

(a)

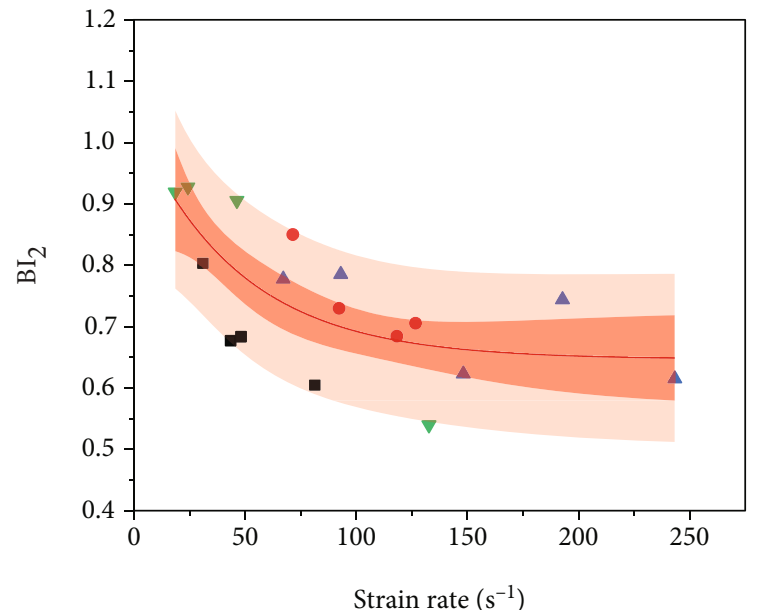

- Lv et al. (19)

- Zhu et.al. (26)

$\Delta$ Zhang et al. (29)

$\nabla$ Li et al. (16)
- Exponential fitting

$90 \%$ Confidence interval

$90 \%$ Prediction interval

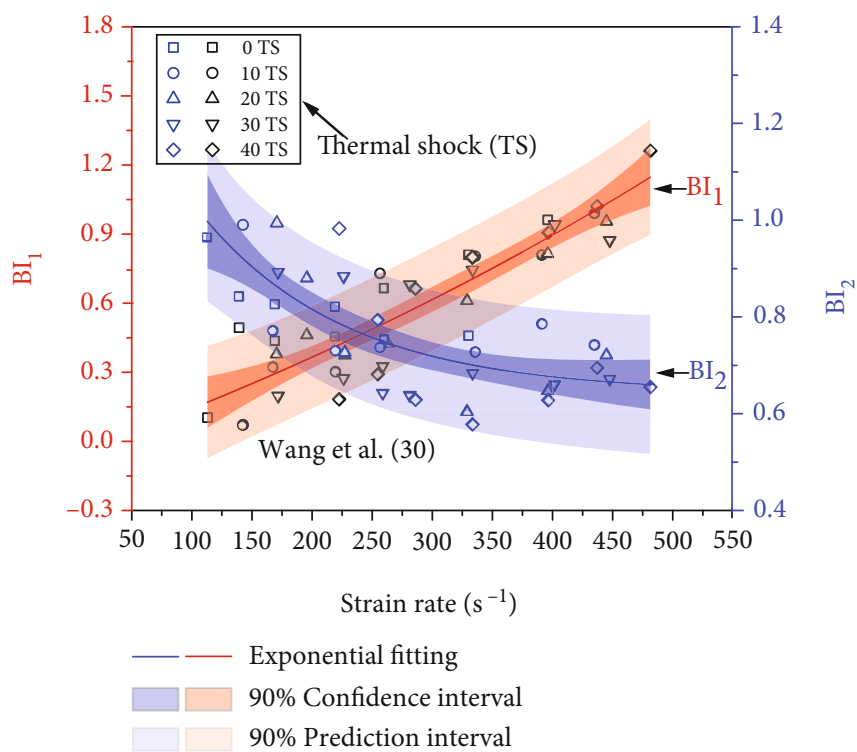

(c)

FIgURE 2: Changes in the $\mathrm{BI}$ of sandstone with strain rate. (a) $\mathrm{BI}_{1}[25,26,51,53]$; (b) $\mathrm{BI}_{2}[25,26,54,60]$; (c) $\mathrm{BI}_{1}$ and $\mathrm{BI}_{2}[58]$.

than $100 \mathrm{~s}^{-1}, \mathrm{BI}_{1}$ decreases rapidly from 0.9 to about 0.7 . When the strain rate is between $100 \mathrm{~s}^{-1}$ and $180 \mathrm{~s}^{-1}$, the $\mathrm{BI}_{1}$ decreases slowly from 0.7 to about 0.65 . At a higher strain rate, with the increase in the strain rate, $\mathrm{BI}_{1}$ increases slowly, while $\mathrm{BI}_{2}$ decreases rapidly, as shown in Figure 2(c).

4.2. Influence of Temperature. To facilitate the comparison of the variation of the brittleness index with temperature, the data for the calculated brittleness indexes from different literature are standardized as shown in equation (3). The $\mathrm{B}$ $\mathrm{I}_{1}{ }^{*}$ and $\mathrm{BI}_{2}{ }^{*}$ denote the standardized brittleness indexes calculated in equations (1) and (2), respectively. Figure 3 shows the variation in the $\mathrm{BI}^{*}$ of sandstone with treatment temperature. It can be seen that under low-temperature conditions, $\mathrm{BI}_{1}{ }^{*}$ and $\mathrm{BI}_{2}{ }^{*}$ both shows a downward trend with increasing temperature, as shown in Figures 3(a) and 3(c). Under hightemperature conditions, $\mathrm{BI}_{1}{ }^{*}$ and $\mathrm{BI}_{2}{ }^{*}$ can be divided into two stages as the temperature increases, but they show 

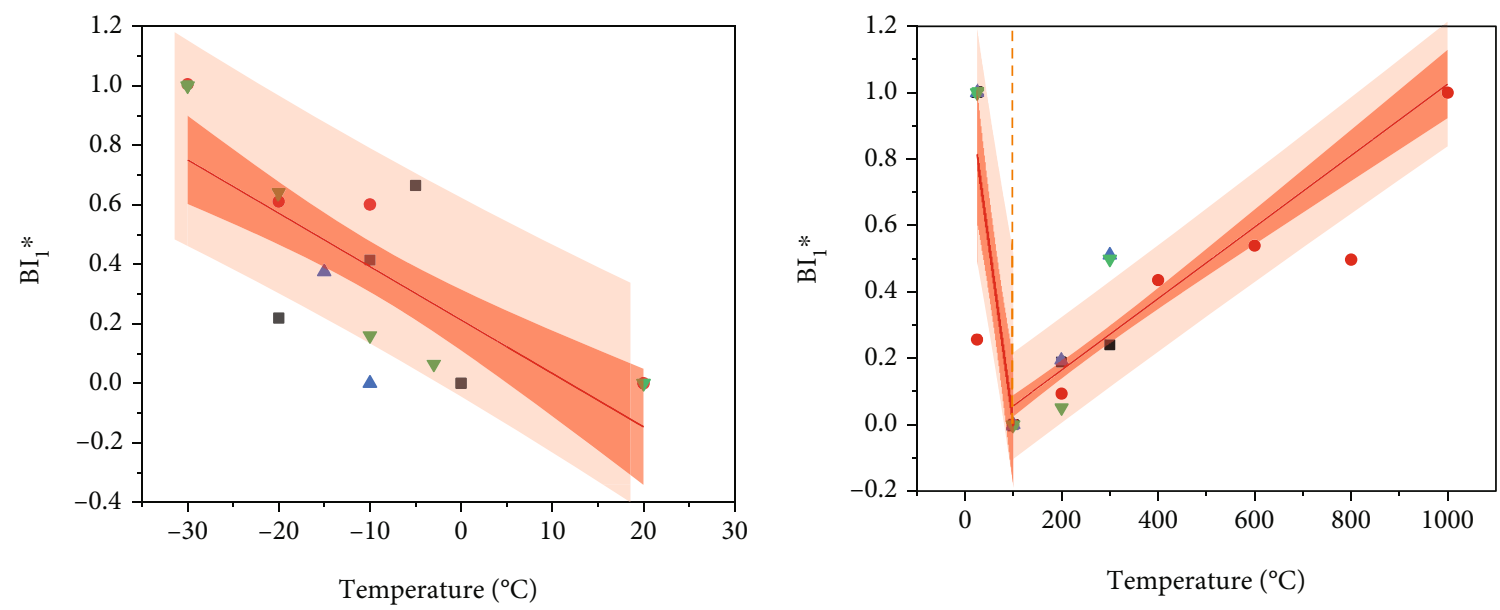

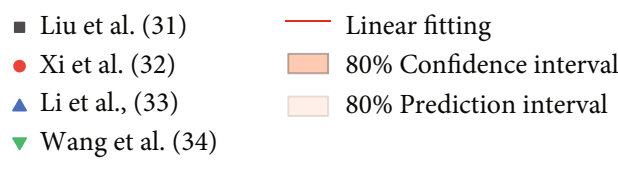

(a)

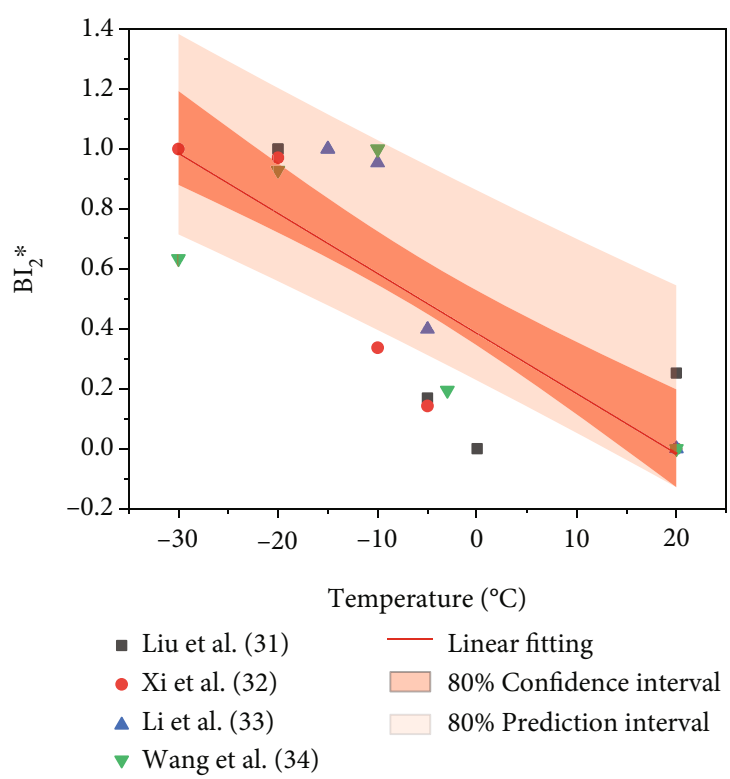

(c)

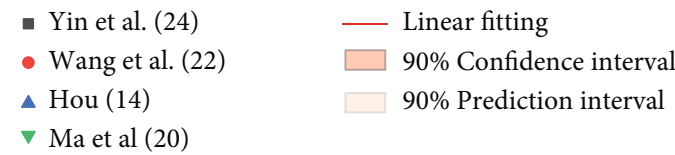

(b)

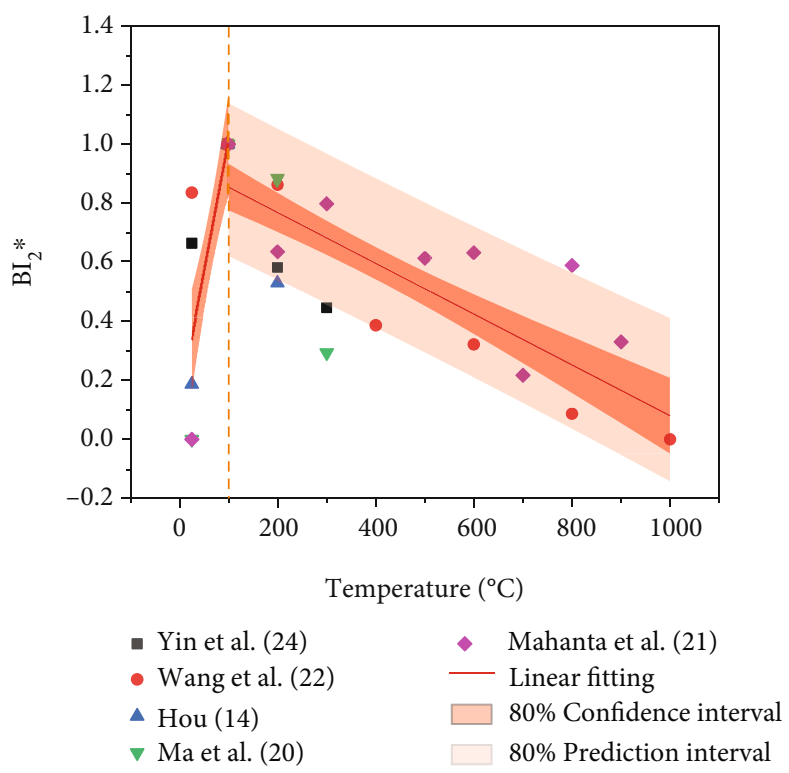

(d)

Figure 3: Changes in the $\mathrm{BI} *$ of sandstone with temperature: $(\mathrm{a}, \mathrm{b}) \mathrm{BI}_{1} *$; (c, d) $\mathrm{BI}_{2} *$. [38, 52, 55-57, 59, 61-63].

opposite trends. When the heating temperature is about $100^{\circ} \mathrm{C}, \mathrm{BI}_{1}{ }^{*}$ drops to the minimum and $\mathrm{BI}_{2}{ }^{*}$ increases to the maximum, as shown in Figures 3(b) and 3(d).

$$
\mathrm{BI}^{*}=\frac{\mathrm{BI}-\mathrm{BI}_{\min }}{\mathrm{BI}_{\max }-\mathrm{BI}_{\min }},
$$

where $\mathrm{BI}^{*}$ represents the standardized brittleness index. BI represents the brittleness index at different temperatures, and $\mathrm{BI}_{\max }$ and $\mathrm{BI}_{\min }$ represent the maximum and minimum values of the brittleness index at different temperatures, respectively.

\section{Discussion}

Brittleness is a very important property of rocks (especially deep rocks). The brittleness of rock is affected by many factors such as mineral composition, Young's modulus, Poisson's ratio, compressive strength, and tensile strength [15-17]. In this paper, the effects of the strain rate and temperature on the brittleness of sandstone were studied and the mechanisms of influence were discussed.

The brittleness of rock is closely related to its failure stress. According to previous studies, the variation in failure stress with a strain rate of brittle materials is shown in Figure 4(a), which is roughly divided into three stages. Among them, point $\mathrm{A}$ is the end of stage $\mathrm{I}$, and the 


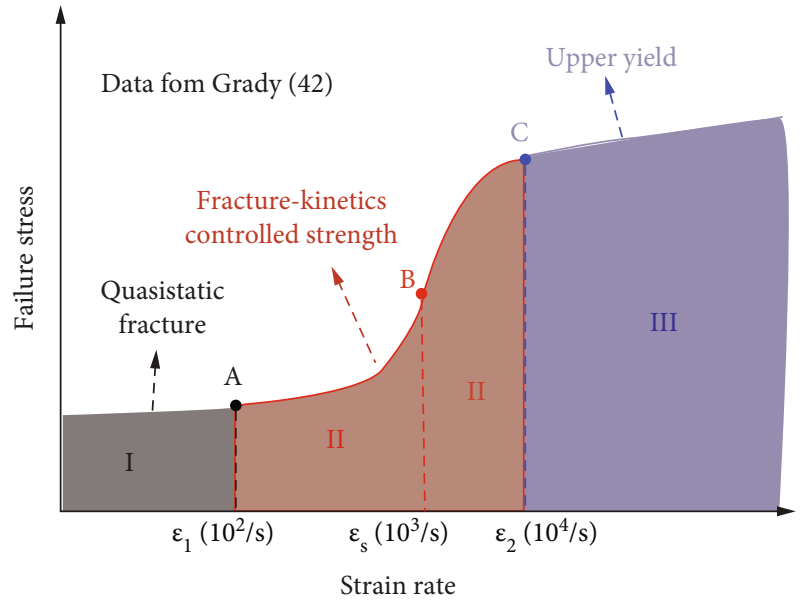

(a)

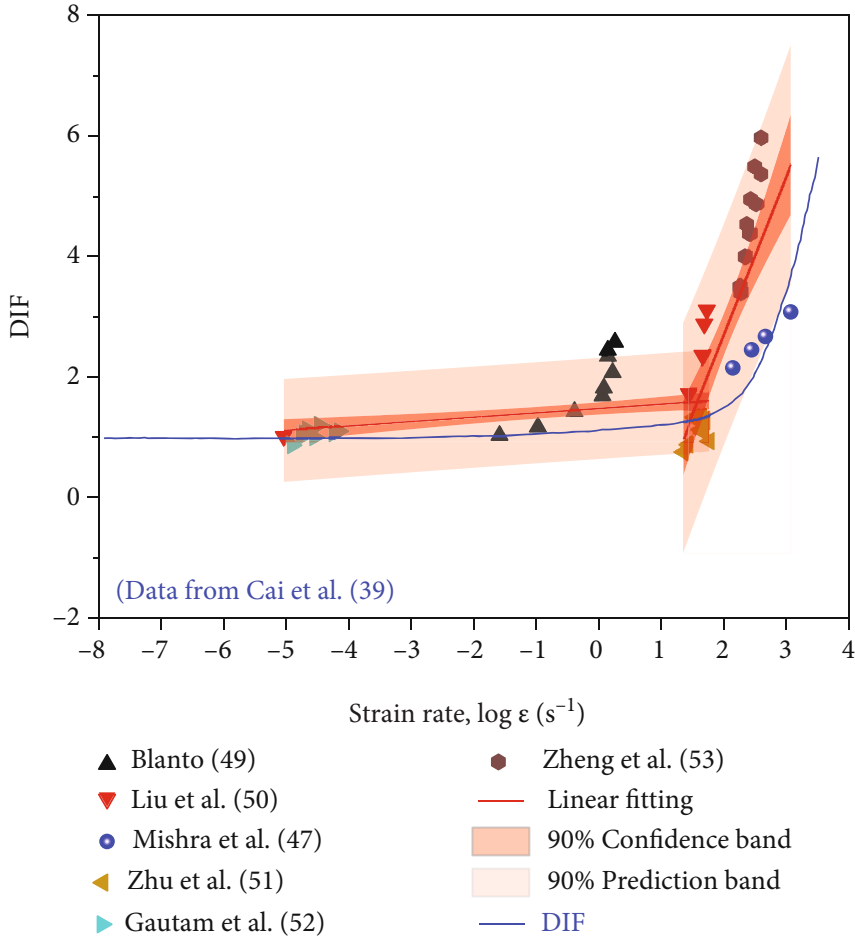

(b)

FIGURE 4: Variations in dynamic strength and dissipated energy with strain rate. (a) Failure stress with strain rate [22]. (b) DIF with strain rate $[30,64-68]$.

corresponding strain $\varepsilon_{1}$ is $10^{2} \mathrm{~s}^{-1}$; point $\mathrm{B}$ is the inflection point of the stage II curve, and the corresponding strain $\varepsilon_{\mathrm{s}}$ is $10^{3} \mathrm{~s}^{-1}$; and point $\mathrm{C}$ is the starting point of stage III, and the corresponding strain $\varepsilon_{2}$ is $10^{4} \mathrm{~s}^{-1}$ [18]. In stage I, that is, in the area of low strain, a quasistatic fracture mainly occurs in rocks. The original pore closures and microcracks in sandstone are compressed and compacted with the increase in the strain rate, resulting in a slow increase in rock strength and brittleness [19]. This stage is mainly controlled by the thermoactivation mechanism [20, 21]. In stage II, with the continuous increase in the strain rate, the fracture damage controlled by dynamics in the sandstone gradually increases [22, 23], and the energy consumed gradually increases [24-26]. The energy required for crack generation is greater than the energy required for crack expansion [27]. In rock dynamics tests, due to the short duration of the impact loading action, the specimen does not have enough time for energy accumulation and can only be used for energy accumulation by increasing the strength of the rock $[11,28,29]$. The dynamic increase coefficient (DIF), which is the ratio of dynamic strength to static strength, is usually used to express the increase in rock strength [30], as shown in Figure 4(b). It can be seen that when $\log \varepsilon$ is close to $2.0 \mathrm{~s}^{-1}$ $\left(\varepsilon=100 \mathrm{~s}^{-1}\right)$, the DIF value increases significantly, which leads to a rapid increase in the brittleness of the rock. When the strain rate is close to $10^{3} \mathrm{~s}^{-1}$ (point $\mathrm{B}$ ), the failure stress growth rate reaches the maximum. In stage II, the macroviscosity mechanism is dominant [31], the inertia of the rock is gradually obvious, and the viscosity coefficient decreases

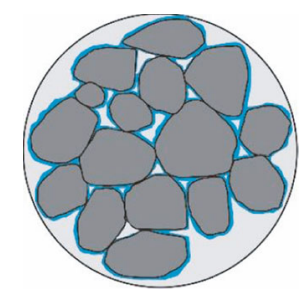

Frozen

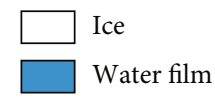

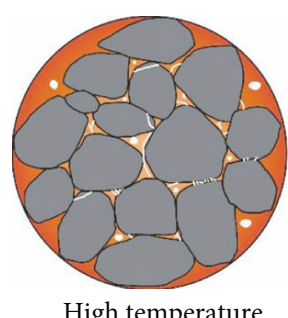

High temperature

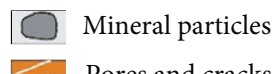

Figure 5: Schematic diagram of low-temperature freezing and high-temperature thermal damage to the rock.

with the increase in the strain rate. When the upper yield is reached in the shock compression process, that is, entering stage III, the rate of increase in rock strength with the increase in the strain rate slows down. With the continuous increase in the strain rate, the rock enters the high strain zone, and defects of different sizes begin to grow in the rock. The sandstone will produce permanent damage, and the rock will change from brittleness to ductility. The strain rates involved in this study includes stage I and a portion of stage II.

The temperature has a great influence on the physical and mechanical properties of sandstone [32]. Under lowtemperature conditions, bulk water, capillary water, and adsorbed water in the rock gradually freeze into ice, and some of the unfrozen adsorbed water forms a water film (as shown in Figure 5) [33]. As the temperature continues to decrease, 


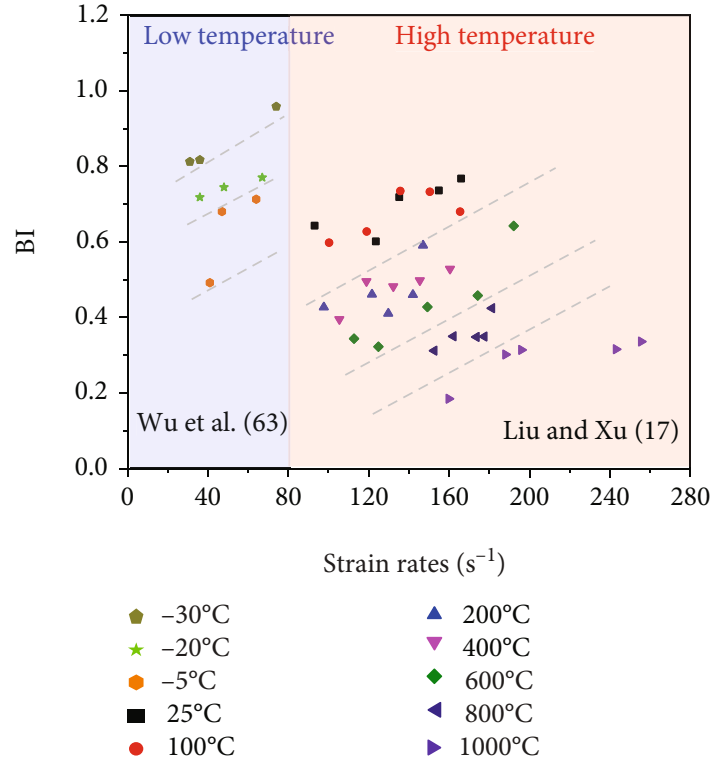

(a)

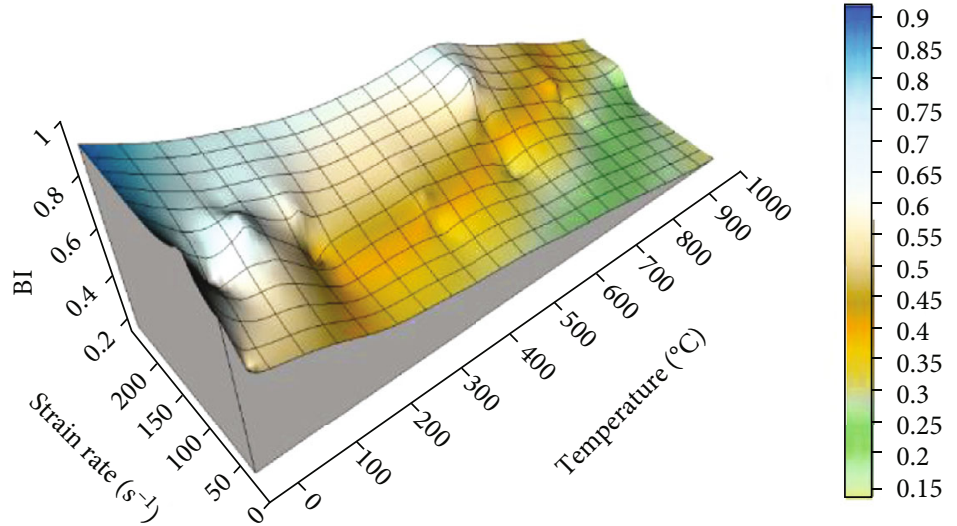

(b)

Figure 6: Relationship between BI and strain rate and temperature [51, 69]: (a) variation in BI with the strain rate at different heat treatment temperatures; (b) 3-D variations of BI with the strain rate and temperature.

the thickness of the unfrozen water film becomes progressively thinner [34]. Due to the supporting force of the ice, the connection force between the mineral particles becomes stronger, and the mineral skeleton becomes more stable, which strengthens the strength of the rock [35]. At the same time, due to the rapid expansion of ice in the formation process, it squeezes the surrounding minerals and produces microcracks, weakening the mechanical properties of the rock [36]. According to the study of Wang et al. [37], during the freezing process of rock, the strengthening effect inhibits the weakening effect, which leads to the continuous increase in the strength of the rock. Therefore, the brittleness of the rock gradually increases as the temperature decreases [38], as shown in the lowtemperature area in Figure 6(a). Under high-temperature conditions, due to the different thermal expansion coefficients of mineral particles [39], nonuniform expansion occurs and thermally induced cracks occur. At the same time, the adsorbed water and crystal water in the sandstone overflowed, causing the pore structure of the sandstone to change [40]. As the temperature continues to rise, different degrees of defects and cracks occur after the rock cools [41, 42]; especially after $400^{\circ} \mathrm{C}$, thermal cracks are gradually obvious, and the internal microcracks of the sandstone increase, the strength decreases, and the brittleness is weakened, as shown in the hightemperature area in Figure 6(a). Around $600^{\circ} \mathrm{C}$, quartz begins to undergo a phase transformation from $\alpha$-quartz to $\beta$-quartz $[43,44]$, and the internal and intergranular cracks between the mineral particles become increasingly serious [45-47]. Under high temperatures, these changes in the internal structure of sandstone lead to a gradual decrease in its strength, reduced brittleness, and enhanced plasticity [48].

In summary, temperature and strain rate have significant effects on the brittleness and plasticity of sandstone due to its water content, pore and crack distribution, mineral struc- ture, and so on. Low temperature and high strain rate are conducive to the enhancement of sandstone brittleness, as shown in Figure $6(\mathrm{~b})$. Both $\mathrm{BI}_{1}$ and $\mathrm{BI}_{2}$ can reflect the brittleness of sandstone but have different applicable conditions. Within the strain rate range of this study, as the strain increases, the internal pores and cracks of the sandstone decrease and the strength of the sandstone increases. For the calculation of $\mathrm{BI}_{1}$, because the prepeak and postpeak elastic moduli are considered, the calculation result is more accurate. Under low-temperature conditions, the strength of sandstone increases, and the $\mathrm{BI}_{1}$ and $\mathrm{BI}_{2}$ changes show the same change trend. However, under high-temperature conditions, the plastic characteristics of sandstone are enhanced, which leads to the unreliable selection of the postpeak elastic modulus of some samples for $\mathrm{BI}_{1}$, so the $\mathrm{BI}_{2}$ value is more reliable. At around $100^{\circ} \mathrm{C}, \mathrm{BI}_{2}$ suddenly increases, which may be due to the high-water content of sandstone. The water evaporates during the heat treatment process, and the original pores and cracks of the sandstone are exposed. When subjected to a load, the strain rate increases, increasing brittleness.

\section{Conclusions}

In this paper, based on existing research data, the variation in the brittleness of sandstone with temperature and strain rate was studied and discussed from a microscopic point of view. At the same time, the variation in sandstone brittleness under the combined action of temperature and strain rate was analyzed. The main conclusions are as follows:

(1) Temperature and strain rate are two important parameters that affect the brittleness of sandstone. Based on previous studies, two empirical formulas 
for the quantitative calculation of sandstone brittleness are selected. Among them, the $\mathrm{BI}_{1}$ method is more accurate in calculating the variation in the sandstone brittleness index with the strain rate, while the $\mathrm{BI}_{2}$ method is more accurate in calculating its variation with temperature

(2) Under dynamic load, with the increase in the strain rate, the failure stress and brittleness of sandstone are positively correlated. When the strain rate exceeds $100 \mathrm{~s}^{-1}$, the failure stress of sandstone begins to increase significantly, resulting in a significant increase in the brittleness index

(3) Under low-temperature conditions, the water inside the rock gradually freezes into ice. Due to the strengthening effect of ice, the strength and brittleness of the rock increase. Under the condition of high temperature, the thermal damage to sandstone is intensified after $400^{\circ} \mathrm{C}$, and the quartz phase changes after $600^{\circ} \mathrm{C}$, which leads to the increase in microcrack density and the decrease in brittleness in sandstone. The conditions of low temperature and high strain rate are beneficial to the enhancement of sandstone brittleness

\section{Notations}

BI: Brittleness index

$\mathrm{BI}^{*}$ : Standardized brittleness index

E: $\quad$ Prepeak elastic modulus

$M$ : Postpeak elastic modulus

$W_{\mathrm{el}}$ : Elastic energy and total energy at failure

$W_{\text {tot }}$ : Slab top surface temperature.

\section{Data Availability}

The data used to support the findings of this study are available from the corresponding author upon request.

\section{Conflicts of Interest}

The authors declare that they have no conflicts of interest.

\section{Acknowledgments}

This research was supported by the National Natural Science Foundation of China (Grant Nos. 41672279, 41807233, and 41972288) and the Natural Science Foundation of Jiangsu Province (Grant No. BK20180662).

\section{References}

[1] J. L. Zhang and B. J. Fu, "Rockburst and its criteria and control," Chinese Journal of Rock Mechanics and Engineering, vol. 27, no. 10, pp. 2034-2042, 2008.

[2] O. Yarali and S. Kahraman, "The drillability assessment of rocks using the different brittleness values," Tunnelling and Underground Space Technology, vol. 26, no. 2, pp. 406-414, 2011.
[3] J. G. Ramsay, Folding and Fracturing of Rocks, McGraw Hill, New York, 1967.

[4] L. Obert and W. I. Duvall, Rock Mechanics and the Design of Structures in Rock, John Wiley Sons, New York, 1967.

[5] D. M. Jarvie, R. J. Hill, T. E. Ruble, and R. M. Pollastro, "Unconventional shale-gas systems: the Mississippian Barnett Shale of North-Central Texas as one model for thermogenic shale-gas assessment," AAPG Bulletin, vol. 91, no. 4, pp. 475-499, 2007.

[6] R. Altindag, "Assessment of some brittleness indexes in rockdrilling efficiency," Rock Mechanics and Rock Engineering, vol. 43, no. 3, pp. 361-370, 2010.

[7] A. W. Bishop, "Progressive failure-with special reference to the mechanism causing it," Proceedings of the Geotechnical Conference on Shear Strength Properties of Natural Soils and Rocks, Oslo, vol. 2, pp. 142-150, 1967.

[8] V. Hajiabdolmajid, P. K. Kaiser, and C. D. Martin, "Modelling brittle failure of rock," International Journal of Rock Mechanics and Mining Sciences, vol. 39, no. 6, pp. 731-741, 2002.

[9] T. Feng, X. B. Xie, W. X. Wang, and C. L. Pan, "Brittleness of rocks and brittleness indexes for describing rockburst proneness," Mining and Metallurgical Engineering, vol. 20, no. 4, pp. 18-19, 2000.

[10] M. Aubertin, D. E. Gill, and R. Simon, "On the use of the brittleness index modified (BIM) to estimate the post-peak behavior of rocks," in Proceedings of the 1st North American Rock Mechanics Symposium, pp. 945-952, Austin, Texas, 1994.

[11] V. Hucka and B. Das, "Brittleness determination of rocks by different methods," International Journal of Rock Mechanics and Mining Sciences \& Geomechanics Abstracts, vol. 11, no. 10, pp. 389-392, 1974.

[12] B. Tarasov and Y. Potvin, "Universal criteria for rock brittleness estimation under triaxial compression," International Journal of Rock Mechanics and Mining Sciences, vol. 59, pp. 57-69, 2013.

[13] F. Meng, L. N. Y. Wong, and H. Zhou, "Rock brittleness indices and their applications to different fields of rock engineering: a review," Journal of Rock Mechanics and Geotechnical Engineering, vol. 13, no. 1, pp. 221-247, 2021.

[14] D. Zhang, P. G. Ranjith, and M. A. S. Perera, “The brittleness indices used in rock mechanics and their application in shale hydraulic fracturing: a review," Journal of Petroleum Science and Engineering, vol. 143, pp. 158-170, 2016.

[15] H. Horii and S. Nemat-nasser, "Brittle failure in compression: splitting, faulting and brittle-ductile transition," Philosophical Transactions of The Royal Society A Mathematical Physical and Engineering Science, vol. 319, no. 1549, pp. 337-374, 1986.

[16] T. F. Wong and P. Baud, "The brittle-ductile transition in porous rock: a review," Journal of Structural Geology, vol. 44, pp. 25-53, 2012.

[17] M. Duda and J. Renner, "The weakening effect of water on the brittle failure strength of sandstone," Geophysical Journal International, vol. 192, no. 3, pp. 1091-1108, 2013.

[18] C. Z. Qi and Q. H. Qian, "Physical mechanism of dependence of material strength on strain rate for rock-like material," Chinese Journal of Rock Mechanics and Engineering, vol. 22, no. 2, pp. 177-181, 2003.

[19] M. Cai, P. K. Kaiser, F. Suorineni, and K. Su, "A study on the dynamic behavior of the Meuse/Haute-Marne argillite," Physics and Chemistry of the Earth, vol. 32, no. 8-14, pp. 907-916, 2007. 
[20] A. Kumar, "The effect of stress rate and temperature on the strength of basalt and granite," Geophysics, vol. 33, no. 3, pp. 501-510, 1968.

[21] P. Perzyna, "Constitutive modelling of dissipative solids for localization and fracture," in Localization and Fracture Phenomena in Inelastic Solids, pp. 99-241, Springer, Vienna, 1998.

[22] D. E. Grady, "Shock-wave properties of brittle solids," Office of Scientific and Technical Information Technical Reports, vol. 370, no. 1, pp. 9-20, 1996.

[23] M. E. Kipp, D. E. Grady, and E. P. Chen, "Strain-rate dependent fracture initiation," International Journal of Fracture, vol. 16, no. 5, pp. 471-478, 1980.

[24] M. Li, Research on Rupture Mechanism of Coal Measures Sandstone under High Temperature and Impact Load, China University of Mining Technology, Xuzhou, China, 2014.

[25] X. F. Li, H. B. Li, K. Liu, Q. B. Zhang, and L. Zou, "Dynamic properties and fracture characteristics of rocks subject to impact loading," Chinese Journal of Rock Mechanics and Engineering, vol. 36, no. 10, pp. 2393-2405, 2017.

[26] J. J. Zhu, X. B. Li, F. Q. Guan, S. M. Wang, and W. He, “Study on dynamic characteristics and damage characteristics of sandstone under impact load," in China Proceedings 6th High-level Forum on Highway science and technology innovation, pp. 278-285, 2013.

[27] D. R. Wang and S. S. Hu, "Influence of aggregate on the compression properties of concrete under impact," Journal of Experimental Mechanics, vol. 17, no. 1, pp. 23-27, 2002.

[28] X. B. Li, T. S. Lok, and J. Zhao, "Dynamic characteristics of granite subjected to intermediate loading rate," Rock Mechanics and Rock Engineering, vol. 38, no. 1, pp. 21-39, 2005.

[29] J. Z. Liu, J. Y. Xu, X. C. Lu, L. Zhang, and Z. D. Wang, "Experimental study on dynamic mechanical properties of amphibolites under impact compressive loading," Chinese Journal of Rock Mechanics and Engineering, vol. 28, no. 10, pp. 21132121, 2009.

[30] S. Mishra, H. Meena, V. Parashar et al., "High strain rate response of rocks under dynamic loading using split Hopkinson pressure bar," Geotechnical \& Geological Engineering, vol. 36, no. 1, pp. 531-549, 2018.

[31] J. D. Campbell and W. G. Ferguson, "The temperature and strain-rate dependence of the shear strength of mild steel," Philosophical Magazine, vol. 21, no. 169, pp. 63-82, 1970.

[32] Z. L. Ge, Q. Sun, L. Xue, and T. Yang, "The influence of microwave treatment on the mode I fracture toughness of granite," Engineering Fracture Mechanics, vol. 249, article 107768, 2021.

[33] J. G. Dash, A. W. Rempel, and J. S. Wettlaufer, "The physics of premelted ice and its geophysical consequences," Reviews of Modern Physics, vol. 78, no. 3, pp. 695-741, 2006.

[34] A. W. Rempel, "Formation of ice lenses and frost heave," Journal of Geophysical Research: Earth Surface, vol. 112, no. F2, 2007.

[35] H. L. Jia, S. Ding, Y. Wang, F. Zi, Q. Sun, and G. S. Yang, “An NMR-based investigation of pore water freezing process in sandstone," Cold Regions Science and Technology, vol. 168, article 102893, 2019.

[36] H. L. Jia, F. Zi, G. S. Yang et al., "Influence of pore water (ice) content on the strength and deformability of frozen argillaceous siltstone," Rock Mechanics and Rock Engineering, vol. 53, no. 2, pp. 967-974, 2020.
[37] T. Wang, Q. Sun, H. L. Jia, J. X. Ren, and T. Luo, "Linking the mechanical properties of frozen sandstone to phase composition of pore water measured by LF-NMR at subzero temperatures," Bulletin of Engineering Geology and the Environment, vol. 80, no. 6, pp. 4501-4513, 2021.

[38] J. M. Xi, G. S. Yang, L. Pang, X. T. Lv, and F. L. Liu, "Experimental study on basic mechanical behaviors of sandy mudstone under low freezing temperature," Journal of China Coal Society, vol. 39, no. 7, pp. 1262-1268, 2014.

[39] Z. L. Ge and Q. Sun, "Acoustic emission characteristics of gabbro after microwave heating," International Journal of Rock Mechanics and Mining Sciences, vol. 138, article 104616, 2021.

[40] Y. Nara, N. Hiroyoshi, T. Yoneda, and K. Kaneko, "Effects of relative humidity and temperature on subcritical crack growth in igneous rock," International Journal of Rock Mechanics and Mining Sciences, vol. 47, no. 4, pp. 640-646, 2010.

[41] J. J. Hu, Q. Sun, and X. H. Pan, "Variation of mechanical properties of granite after high-temperature treatment," Arabian Journal of Geosciences, vol. 11, no. 2, pp. 1-8, 2018.

[42] J. J. Hu, H. P. Xie, Q. Sun, C. B. Li, and G. K. Liu, "Changes in the thermodynamic properties of alkaline granite after cyclic quenching following high temperature action," International Journal of Mining Science and Technology, vol. 31, no. 5, pp. 843-852, 2021.

[43] I. Ohno, "Temperature variation of elastic properties of $\alpha$ quartz up to the $\alpha-\beta$ transition," Journal of Physics of the Earth, vol. 43, no. 2, pp. 157-169, 1995.

[44] I. Ohno, K. Harada, and C. Yoshitomi, “Temperature variation of elastic constants of quartz across the $\alpha$ - $\beta$ transition," Physics and Chemistry of Minerals, vol. 33, no. 1, pp. 1-9, 2006.

[45] W. H. Somerton and G. D. Boozer, "Thermal characteristics of porous rocks at elevated temperatures," Journal of Petroleum Technology, vol. 12, no. 6, pp. 77-81, 1960.

[46] H. C. Heard and L. Page, "Elastic moduli, thermal expansion, and inferred permeability of two granites to $350^{\circ} \mathrm{C}$ and 55 megapascals," Journal of Geophysical Research, vol. 87, no. B11, pp. 9340-9348, 1982.

[47] H. F. Wang, B. P. Bonner, S. R. Carlson, B. J. Kowallis, and H. C. Heard, "Thermal stress cracking in granite," Journal of Geophysical Research, vol. 94, no. B2, pp. 1745-1758, 1989.

[48] G. Wu, D. Y. Wang, and S. T. Zhai, "Acoustic emission characteristics of sandstone after high temperature under uniaxial compression," Rock and Soil Mechanics, vol. 33, no. 11, pp. 3237-3242, 2012.

[49] F. Q. Gong, X. F. Si, X. B. Li, and S. Y. Wang, "Dynamic triaxial compression tests on sandstone at high strain rates and low confining pressures with split Hopkinson pressure bar," International Journal of Rock Mechanics and Mining Sciences, vol. 113, pp. 211-219, 2019.

[50] Y. Hou, Experimental Study on Mechanical Properties of Deep Fine Sandstone under Impact Load, Henan University Technology, Henan, China, 2015.

[51] S. Liu and J. Y. Xu, "Effect of strain rate on the dynamic compressive mechanical behaviors of rock material subjected to high temperatures," Mechanics of Materials, vol. 82, pp. 2838, 2015.

[52] Y. Liu, K. Pan, and X. G. Zhou, "Study on impact failure properties of post-peak cracked sandstone," Journal of West Anhui University, vol. 34, no. 2, pp. 123-127, 2018. 
[53] X. C. Lv, J. Y. Xu, H. H. Ge, D. H. Zhao, and E. L. Bai, "Effects of confining pressure on mechanical behaviors of sandstone under dynamic impact loads," Chinese Journal of Rock Mechanics and Engineering, vol. 29, no. 1, pp. 193-201, 2010.

[54] D. F. Ma, Y. Hou, D. N. Chen, H. R. Wang, and G. Y. Wang, "Compression tests and failure characteristic research of fine sandstones under impact loading," Acta Armamentarii, vol. 37, no. 2, pp. 42-48, 2016.

[55] B. Mahanta, P. G. Ranjith, V. Vishal, and T. N. Singh, "Temperature-induced deformational responses and microstructural alteration of sandstone," Journal of Petroleum Science and Engineering, vol. 192, article 107239, 2020.

[56] P. Wang, J. X. Xu, S. Liu, and T. F. Chen, "Research on dynamic mechanical properties of sandstone at high temperature," Acta Armamentarii, vol. 32, no. 2, pp. 203-208, 2013.

[57] P. Wang, J. Y. Xu, S. H. Liu, and H. Y. Wang, "Dynamic mechanical properties and deterioration of red-sandstone subjected to repeated thermal shocks," Engineering Geology, vol. 212, pp. 44-52, 2016.

[58] T. B. Yin, X. B. Li, Z. L. Zhou, L. Hong, and Z. Y. Ye, "Study on mechanical properties of post-high-temperature sandstone," Chinese Journal of Underground Space and Engineering, vol. 12, no. 6, pp. 1060-1063, 2007.

[59] T. B. Yin, X. B. Li, B. Wang, Z. Q. Ying, and J. F. Jin, "Mechanical properties of sandstones after high temperature under dynamic loading," Chinese Journal of Geotechnical Engineering, vol. 33, no. 5, pp. 777-784, 2011.

[60] Y. Zhang, Q. W. Li, M. Li, and M. Cui, "Research into the dynamic mechanical characteritics of sandstone under different strain rate," China Mining Magazine, vol. 24, no. 2, pp. 162-166, 2015.

[61] Q. S. Liu, G. M. Xu, Y. H. Hu, and X. Chang, "Study on basic mechanical behaviors of rocks at low temperatures," Key Engineering Materials, vol. 306-308, pp. 1479-1484, 2006.

[62] C. Li, G. Y. Cao, Y. W. Wu, Y. S. Huang, and Z. M. Huang, "Experimental study on frozen uniaxial strength of Jurassic sandstone in western China," Journal of Henan University of Urban Construction, vol. 28, no. 2, pp. 39-44, 2019.

[63] H. Y. Wang and Q. Zhang, "Mechanical behavior of frozen porous sandstone under uniaxial compression," Geofluids, vol. 2021, Article ID 1872065, 6 pages, 2021.

[64] T. L. Blanton, "Effect of strain rates from $10^{-2}$ to $10 \mathrm{sec}^{-1}$ in triaxial compression tests on three rocks," International Journal of Rock Mechanics and Mining Sciences \& Geomechanics Abstracts, vol. 18, no. 1, pp. 47-62, 1981.

[65] J. Z. Liu, J. Y. Xu, X. C. Lv, D. H. Zhao, and B. L. Leng, "Experimental study on dynamic mechanical properties of amphibolites, sericite-quartz schist and sandstone under impact loadings," International Journal of Nonlinear ences and Numerical Simulation, vol. 13, no. 2, pp. 209-217, 2012.

[66] J. J. Zhu, X. B. Li, F. Q. Gong, S. M. Wang, and W. He, "Experimental test and damage characteristics of sandstone under uniaxial impact compressive loads," Journal of Central South University, vol. 43, no. 7, pp. 2701-2707, 2012.

[67] P. Gautam, A. K. Verma, M. K. Jha, K. Sarkar, T. N. Singh, and R. K. Bajpai, "Study of strain rate and thermal damage of Dholpur sandstone at elevated temperature," Rock Mechanics and Rock Engineering, vol. 49, no. 9, pp. 3805-3815, 2016.
[68] G. H. Zheng, J. Y. Xu, P. Wang, S. Liu, and H. Y. Wang, "Research on strain rate effects of red-sandstone under water-rock coupling," Chinese Journal of Underground Space and Engineering, vol. 13, no. 1, pp. 79-85, 2017.

[69] J. H. Wu, H. B. Wang, Q. Zong, and Y. Xu, "Experimental investigation of dynamic compression mechanical properties of frozen fine sandstone," Advances in Civil Engineering, vol. 2020, Article ID 8824914, 10 pages, 2020. 